\title{
Função do interferon-tau durante o reconhecimento materno da gestação em ruminantes
}

\author{
The role of interferon-tau during maternal recognition of pregnancy in ruminants
}

\author{
Alfredo Quites Antoniazzi ${ }^{I}$ Luiz Ernani Henkes ${ }^{I I}$ João Francisco Coelho Oliveira ${ }^{\text {III }}$ \\ Thomas Ross Hansen ${ }^{\text {IV }}$
}

\section{-REVISÃO BIBLIOGRÁFICA-}

\section{RESUMO}

O reconhecimento materno da gestação é o periodo em que o concepto sinaliza sua presença para a mãe. Em ruminantes, este periodo coincide com o alongamento do embrião e a máxima produção de interferon-tau (IFNT). $O$ IFNT produzido pelo concepto age via parácrina no útero inibindo a expressão dos receptores de estrógenos (ESR1) e de ocitocina (OXTR) no epitélio luminal do endométrio, evitando, assim, a liberação de pulsos luteolíticos de prostaglandina F2 alfa $(P G F 2 \alpha)$, hormonio responsável pelo início da luteólise. Além da sua ação durante o reconhecimento materno da gestação em ruminantes, o IFNT aumenta a expressão de vários genes estimulados por interferons (ISGs) no útero, no corpo lúteo (CL) e em células sanguíneas. Estudos recentes demonstraram que o IFNT possui ação endócrina no CL ovino e também estende o ciclo estral (pseudo gestação) além do dia 32 após a infusão de IFNT recombinante ovino (roIFNT) na veia uterina. A comprovação da saída de IFNT do útero pela veia uterina sugere que a ação endócrina do IFNT possa ser um mecanismo complementar ao mecanismo intrauterino de reconhecimento materno da gestação. A ação direta do IFNT em tecidos extrauterinos estimula a expressão de ISGs que, no $C L$, podem estar envolvidos com a resistência luteal à ação luteolítica da PGF2a.

Palavras-chave: interferon-tau, reconhecimento materno da gestação, ISG15, ruminantes.

\begin{abstract}
Maternal recognition of pregnancy is the period when the conceptus signals its presence to the dam. In ruminants, it requires conceptus elongation, which coincides with maximum production of interferon-tau (IFNT). Conceptus IFNT acts in a paracrine manner silencing estrogen receptor alpha (ESR1) and oxytocin receptor (OXTR) in the luminal epithelium, thus preventing luteolytic prostaglandin F2 alpha (PGF2 $\alpha$ ) pulses. Besides its role during maternal recognition of pregnancy, IFNT induces the expression of several interferon stimulated genes (ISGs) in the endometrium, corpus luteum (CL) and blood cells. Recently, it was suggested an endocrine role for IFNT during the period of maternal recognition of pregnancy in sheep. It was demonstrated that infusion of IFNT into the uterine vein can extend the estrous cycle beyond 32 days. This direct action of IFNT in extrauterine tissues induces ISGs expression, which might be involved in the rescue of the $C L$ from the luteolytic effects of $P G F 2 \alpha$ pulses.
\end{abstract}

Key words: interferon-tau, maternal recognition of pregnancy, ISG15, ruminants.

\section{INTRODUÇÃO}

O reconhecimento materno da gestação pode ser definido como o período em que o concepto sinaliza sua presença para a mãe. Em ruminantes, este

'Programa de Pós-graduação em Medicina Veterinária (PPGMV), Departamento de Clínica de Grandes Animais, Universidade Federal de Santa Maria (UFSM), 97105-900, Santa Maria, RS, Brasil. Email: alfredo.antoniazzi@biorep.ufsm.br . Autor para correspondência.

"Faculdade de Medicina Veterinária, Universidade Federal do Pampa (Unipampa), Uruguaiana, RS, Brasil.

IIIDepartamento de Clínica de Grandes Animais, UFSM, Santa Maria, RS, Brasil.

${ }^{\text {IV }}$ Department of Biomedical Sciences, Colorado State University, Fort Collins, CO, USA. 
período requer o alongamento do embrião, que coincide com a máxima produção de interferon-tau (IFNT). O IFNT é um produto secretado em grandes quantidades pelas células do trofoblasto do concepto (embrião e anexos embrionários) de ruminantes antes da implantação (FARIN et al., 1989; GUILLOMOT et al., 1990; GRAY et al., 2002). É classificado como interferon do tipo I e sua principal função é evitar o retorno à ciclicidade, preservando o funcionamento do corpo lúteo (CL) durante a gestação (para revisão ROBERTS et al., 2008). O IFNT produzido pelo concepto age de maneira parácrina no útero, inibindo a expressão dos receptores de estrógeno (ESR1) e de ocitocina (OXTR) no epitélio luminal do endométrio, evitando assim, a liberação de pulsos luteolíticos de prostaglandina F2 alfa (PGF2 $\alpha$; SPENCER \& BAZER, 1996), hormônio responsável pelo início da luteólise (MCCRACKEN et al., 1970). O IFNT liga-se a receptores de interferon tipo I (IFNAR1 e IFNAR2) com sinalização via Jak/ STAT (BINELLI et al., 2001). Além da sua ação durante o reconhecimento materno da gestação em ruminantes, o IFNT induz a expressão de vários genes estimulados por interferons (ISGs) no útero (MIRANDO et al., 1991), e em células sanguíneas (YANKEY et al., 2001; HAN et al., 2006).

Dados recentes reportam a expressão de ISGs no CL e em outros tecidos extrauterinos durante o início da prenhez em ovelhas, sugerindo uma ação endócrina do IFNT (OLIVEIRA et al., 2008). A ISG15 (gene estimulado por inteferon 15) é uma proteína que possui função semelhante a uma ubiquitina (AUSTIN et al., 1996) e é expressa no útero durante o início da gestação em resposta ao IFNT. Contudo, por meio de imunohistoquímica, sua presença foi também detectada em células luteais grandes do CL de ovelhas no dia 15 da gestação (OLIVEIRA et al., 2008). A ação endócrina do IFNT foi corroborada pela infusão de IFNT recombinante ovino (roIFNT), por sete dias, na veia uterina de ovelhas (BOTT et al., 2010). Nesse estudo foi infundida uma dose de roIFNT $\left(2 \times 10^{7} \mathrm{UI} 24 \mathrm{~h}^{-1}\right)$ equivalente àquela detectada por meio de um ensaio antiviral realizado com sangue da veia uterina de ovelhas prenhes. A resposta antiviral típica de interferons tipo I foi compatível com a produção de IFNT durante o reconhecimento materno da gestação. A atividade específica do IFNT foi comprovada com ensaios antivirais em que as amostras de soro de animais no $15^{\circ}$ dia da gestação foram tratadas com anticorpo anti-IFNT e não foi observada atividade antiviral. Confirmou-se assim, que a atividade detectada anteriormente referente a interferons do tipo I era de fato correspondente à atividade do IFNT originário do concepto. Adicionalmente, pela primeira vez foi relatada a extensão do ciclo (pseudo gestação) além do dia 32, com a infusão na veia uterina de roIFNT por sete dias (BOTT et al., 2010).

A comprovação da saída de IFNT do útero, pela veia uterina, sugere que sua ação endócrina pode estar relacionada a um mecanismo complementar ao mecanismo intrauterino de reconhecimento materno da gestação. Essa ação direta do IFNT em tecidos extrauterinos estimula a expressão de ISGs, que no CL, podem estar envolvidos com a resistência luteal à ação luteolítica da PGF2 $\alpha$. Esta revisão aborda desde a estrutura do CL, luteólise, ação de prostaglandinas endometriais e luteais, mecanismo clássico do reconhecimento materno da gestação em ruminantes (parácrino), mecanismo de ação e função endócrina do IFNT.

\section{Corpo lúteo e luteólise}

O CL é descrito como uma glândula temporária formada a partir de um folículo que ovulou, tendo como sua secreção primária a progesterona, esteroide necessário para a ciclicidade ovariana e o estabelecimento e manutenção da gestação na maioria dos mamíferos (MCCRACKEN et al., 1999; NISWENDER et al., 2000; DAVIS \& RUEDA, 2002). No CL de ovinos, foram isolados e identificados dois tipos de células esteroidogênicas; as células grandes e as células pequenas, que podem ser identificadas mediante características morfológicas e bioquímicas (FITZ et al., 1982; NISWENDER et al., 1985). As células luteais grandes secretam aproximadamente sete vezes mais progesterona, quando não estimuladas por agente luteotrófico, quando comparadas com as pequenas (KENNY et al., 1989). Adicionalmente, estas células são consideradas esteroidogênicas constitutivas, porque apresentam a proteína quinase A (PKA) constitutivamente ativa (BOGAN \& NISWENDER, 2007). A progesterona induz diferenciação do estroma uterino, estimula secreções das glândulas endometriais, acúmulo de vacúolos basais no epitélio glandular e modifica o padrão de secreção de proteínas pelas células endometriais. Essas proteínas são responsáveis por proporcionar o ambiente uterino apropriado para o desenvolvimento inicial do embrião (para revisão BAZER et al., 1986).

Ao final da fase luteal, a progesterona causa inibição de seus próprios receptores, permitindo um retorno da ação estrogênica centralmente no hipotálamo e, de modo periférico, no útero (MCCRACKEN et al., 1999), levando a um rápido aumento na expressão de ESR1 (SPENCER \& BAZER, 1996). Os estrógenos determinam o aumento da expressão de OXTR no endométrio (SPENCER \& 
BAZER, 1996) e a liberação de ocitocina pela hipófise posterior. Por sua vez, a ligação da ocitocina com seu receptor estimula a síntese e secreção de PGF2 $\alpha$ responsável pelo início da luteólise (WATHES \& LAMMING 1995).

Em bovinos, ovinos e suínos, a artéria ovariana está em íntima aposição à veia útero ovariana, mas, somente na vaca e na ovelha, a área de contato está aumentada em função da artéria apresentar um tortuoso caminho sobre a veia (GINTHER, 1974). Quando se injeta PGF2 $\alpha$ na veia uterina de ovelhas, esta substancia passa diretamente para a artéria ovariana ipsilateral (MCCRACKEN et al., 1973). Assim, a PGF2 $\alpha$ produzida no utero é transferida para os ovários pelo mecanismo de contra corrente estabelecido entre a veia uterina e a artéria ovariana (GINTHER, 1974).

A produção intraluteal de prostaglandinas já foi descrita em várias espécies (MCCRACKEN et al., 1999; NISWENDER etal., 2000; DAVIS \& RUEDA, 2002) e existem evidências que sugerem o funcionamento de um sistema luteal de metabolismo, transporte e sinalização de PGE2 e PGF2 $\alpha$, sugerindo que as prostaglandinas luteais possam contribuir para a autorregulação do CL (HAYASHI et al., 2003; AROSH et al., 2004). Adicionalmente, a estimulação luteal pela PGF2 $\alpha$ aumenta a liberação de ocitocina luteal (FLINT $\&$ SHELDRICK, 1982), que potencializa a liberação de PGF2 $\alpha$ uterina (WATHES \& LAMMING, 1995) e luteal (SHIRASUNA et al., 2007).

Receptores de prostaglandinas

Sintetizadas a partir do ácido araquidônico, as prostaglandinas difundem-se fracamente pelas membranas celulares (SCHUSTER, 1998). APGF2 $\alpha$ e a PGE2 exercem seus efeitos primariamente a partir de receptores acoplados à proteína $\mathrm{G}$, denominados $\mathrm{PTGFR}$ e PTGER, respectivamente (WILTBANK et al., 1995). O PTGFR foi clonado em bovinos (SAKAMOTO et al., 1994) e ovinos (GRAVES et al., 1995). O PTGER possui subtipos 1, 2, 3, e 4, e o PTGFR possui os subtipos A e B (NARUMIYA et al., 1999). As isoformas do PTGFRA e B, em ovinos, possuem a mesma sequência de aminoácidos, porém a forma A possui 46 aminoácidos adicionais, sugerindo que a forma $B$ é truncada em relação à A (PIERCE et al., 1997). Em bovinos, estudos com CL demonstraram a presença de receptores PTGFR, em células endoteliais e células luteais pequenas, em quantidade pouco significativa, ao contrário das células luteais grandes, nas quais esses receptores são abundantes (SAKAMOTO et al., 1994). Já em ovelhas, o PTGFR foi identificado somente nas células luteais grandes, enquanto que as células luteais pequenas não respondem à ação da PGF2 $\alpha$ (NISWENDER, 2002). A resposta luteal à PGF2 $\alpha$ é a diminuição da síntese de progesterona, pela diminuição da captação e do transporte de colesterol celular e pela diminuição da expressão de enzimas esteroidogênicas (NISWENDER et al., 2000).

Reconhecimento materno da gestação

O reconhecimento materno da gestação pode ser definido como os diferentes modos pelos quais a mãe reage à existência de um concepto que sinaliza sua presença. Este tipo de comunicação ocorre em diversos momentos durante a gestação, mas em ruminantes, é vital a intervenção do concepto para a manutenção do CL mediante a atenuação da secreção luteolítica de PGF2 $\alpha$ (ROBERTS et al., 1996). Experimentos pioneiros realizados na década de 60 (MOOR \& ROWSON, 1966), forneceram evidências indicando que o reconhecimento da gestação na ovelha ocorre entre os dias 12 e 13 da prenhez. Experimentos com transferência de embriões para úteros com segmentos isolados observaram que os embriões transferidos eram capazes de manter $80 \%$ dos CLs adjacentes ao corno uterino gravídico. Por outro lado, os transferidos para o corno uterino contralateral não tiveram efeito na manutenção luteal. Quando a transferência dos embriões foi realizada em receptoras com CL nos dois ovários, o embrião foi capaz de manter somente o ipsilateral (MOOR \& ROWSON, 1966).

No final da década de 70, estabeleceu-se que a manutenção do CL no início da gestação era resultado da produção de um fator proteico produzido pelo concepto (MARTAL et al., 1979). Posteriormente, no início da década de 80 , foi purificada uma proteína secretada pelo concepto ovino com características de uma antiluteolisina. Essa proteína, inicialmente chamada de proteína X (GODKIN et al., 1982) e posteriormente denominada trofoblastina ovina (oTP1), era o principal produto de conceptos ovinos em cultura, sendo secretada em maior abundância entre os dias 10 e 12 da prenhez (GODKIN et al., 1984). Subsequentemente, essa proteína teve sua função antiluteolítica comprovada e associada ao reconhecimento materno da gestação. Após seu sequenciamento (IMAKAWA et al., 1987), foi renomeada IFNT (ROBERTS et al., 1989; ROBERTS et al., 1992), devido à sua semelhança estrutural com os interferons tipo I. Essa associação despertou muito interesse, pois além das funções antivirais e imunomoduladoras conhecidas dos interferons, essa proteína possuía ação no contexto reprodutivo.

O concepto ovino secreta IFNT entre o $10^{\circ}$ e o $25^{\circ}$ dia, com pico de secreção entre os dias 14 e 16 da gestação (ROBERTS et al., 1996). Já no bovino, a 
secreção ocorre entre o $12^{\circ}$ e o $26^{\circ}$ dia, com pico entre os dias 15 e 16 (FARIN et al., 1990; ROBERTS, 1991; ROBERTS et al., 1991). Como resposta, o IFNT inibe a transcrição de receptores de estrógenos (ESR1; SPENCER \& BAZER, 1996) e ocitocina (OXTR; SPENCER \& BAZER, 1996; CHEN et al., 2006) no endométrio inibindo a luteólise (ZARCO et al., 1988a; ZARCO et al., 1988b). Na ovelha, esse momento corresponde à elongação do blastocisto que passa de uma forma esférica para filamentosa entre os dias $10 \mathrm{e}$ 17 da gestação (SPENCER et al., 2004) (Figura 1).

$\mathrm{O}$ gene do interferon-tau

O gene do IFNT possui uma homologia de aproximadamente $70 \%$ com o interferon-ômega de humanos (ROBERTS et al., 2003) e apresenta uma única matriz de leitura aberta (do inglês open reading frame) de 595 pares de bases. Esta codifica uma sequência primária (pré-proteína) de 195 aminoácidos com uma região sinalizadora com 23 aminoácidos, a qual é clivada para formar a proteína de 172 aminoácidos (ROBERTS et al., 2003). O início da expressão do gene do IFNT parece ser programado de um modo geneticamente independente do ambiente uterino uma vez que ele é expresso em sistemas in vivo e in vitro. No entanto, a produção de IFNT é influenciada pelo ambiente uterino, pois sua produção in vitro aumenta na presença de tecido uterino (KERBLER et al., 1997). A expressão de IFNT termina com a implantação, pois o contato do trofoblasto com o endométrio cessa sua produção (DEMMERS et al., 2001). Recentemente, foram identificados alguns fatores de transcrição que possuem papel importante na regulação da expressão do gene do IFNT. Dentre eles, o fator de transcrição Ets2 possui um papel fundamental na regulação da transcrição de IFNT durante o início da prenhez (EZASHI et al., 1998); para revisão (EALY \& YANG, 2009).

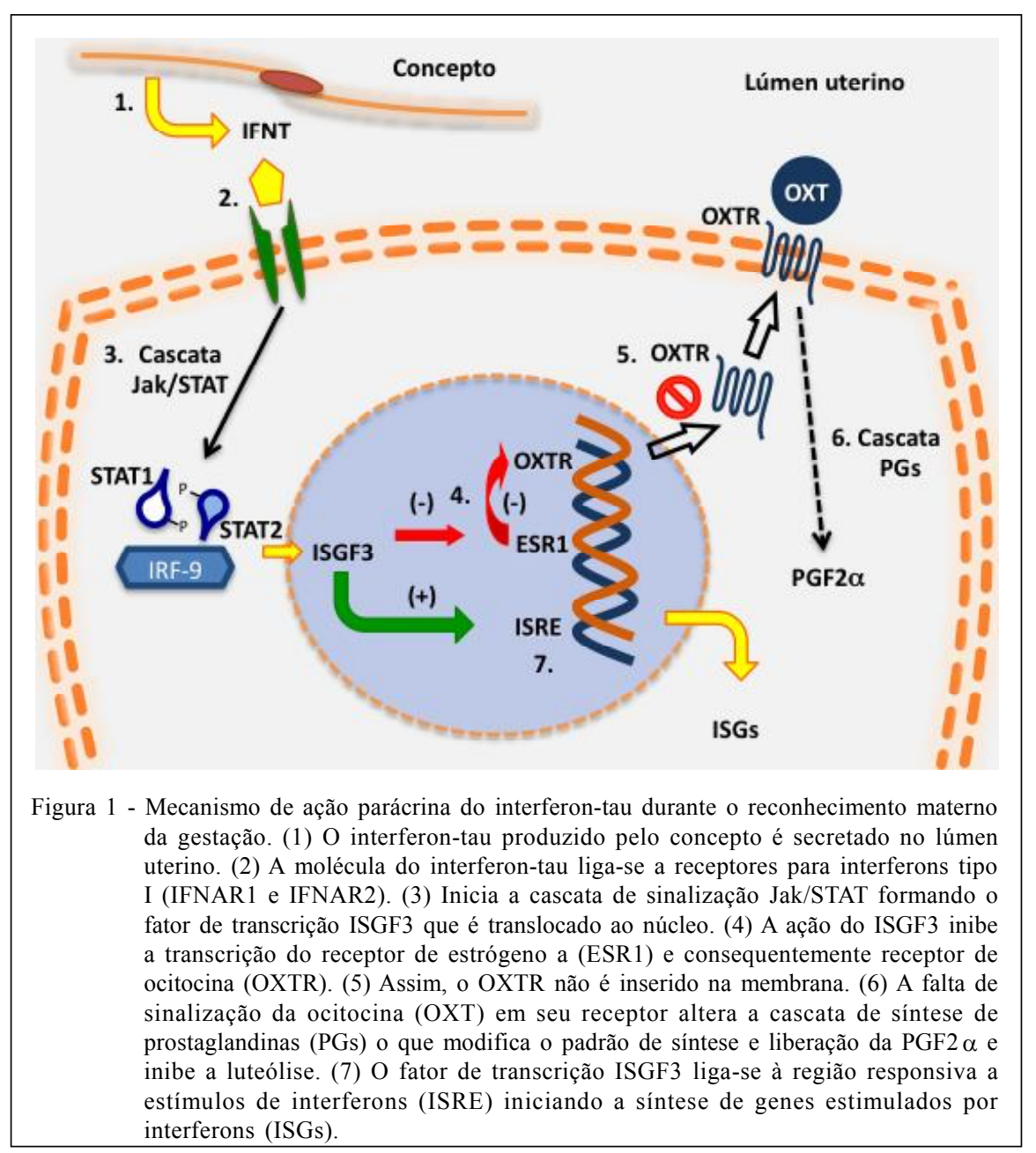

Ciência Rural, v.41, n.1, jan, 2011. 
Receptores de interferon tipo I e genes estimulados por interferons (ISGs)

Os receptores de interferon tipo I (IFNAR1 e IFNAR2) são expressos em todos os tecidos corporais e têm como função principal mediar respostas antivirais. Também estão localizados no útero para mediar respostas maternas em função do IFNT produzido pelo concepto (ROSENFELD et al., 2002). O IFNT se liga a esses receptores para exercer sua ação pela via de transdução de sinais Jak/STAT, onde as proteínas tirosino-quinases fosforilam proteínas STAT formando complexos multiméricos que agem como fatores de transcrição (BINELLI et al., 2001). Esses complexos se ligam a regiões definidas no DNA chamadas de elementos responsivos à estimulação por interferons (ISREs) que regulam a expressão de ISGs (HANSEN et al., 1999). Dentre os ISGs que aumentam sua expressão durante o início da gestação em resposta ao IFNT, estão o 2',5' oligoadenilato sintetase (OAS; MIRANDO et al., 1991; SCHMITT et al., 1993; JOHNSON et al., 2001), o gene de resistência ao myxovirus 1 (MX1; (OTT et al., 1998) e o gene estimulado pelo interferon 15 (ISG15; NAIVAR et al., 1995; AUSTIN et al., 1996; JOHNSON et al., 1999). Estudos recentes demonstraram a expressão de ISGs em células do sangue (YANKEY et al., 2001; HAN et al., 2006; GIFFORD et al., 2007) e CL (OLIVEIRA et al., 2008; BOTT et al., 2010) logo após a sinalização por IFNT no início da gestação em ruminantes.

A ISG15 recebeu inicialmente o nome de proteína com reação cruzada à ubiquitina por apresentar reação cruzada com o anticorpo contra ubiquitina (AUSTIN et al., 1996). Além disso, também foi demonstrado que ela está aumentada no endométrio de ruminantes (AUSTIN et al., 1996; HANSEN et al., 1997; PERRY et al., 1999; THATCHER et al., 2001), camundongos (AUSTIN et al., 2003) e primatas (BEBINGTON et al., 1999) em resposta à gestação. A ISG15 pode conjugar-se covalentemente a outras proteínas (LOEB \& HAAS, 1992).

Ação endócrina do interferon-tau

Algumas hipóteses foram levantadas para explicar a ação endócrina do IFNT durante o reconhecimento materno da gestação. Foi proposta a presença de um mediador da ação do IFNT; uma interferomedina (SPENCER et al., 1999). Outra hipótese sugerida foi que o IFNT poderia deixar o útero utilizando a via linfática. Para testar essa última, avaliouse a expressão de ISG15 (que reflete altos níveis de IFNT) no dia 15 do ciclo estral ou no início da gestação, em linfonodos que drenam o útero (ilíacos) e a cabeça (submandibulares). Se a hipótese fosse verdadeira, seria esperado que no dia 15 da gestação, os linfonodos ilíacos apresentassem uma maior expressão de ISG15 quando comparados com os submandibulares. Entretanto, nenhuma diferença foi observada (ANTONIAZZI et al., dados não publicados). Esses resultados indicam que o IFNT não utiliza via linfática para atingir a circulação sistêmica.

Estudos recentes avaliaram a expressão de ISG15 em tecidos extrauterinos durante o início da gestação em ovinos (OLIVEIRA et al., 2008; BOTT et al., 2010). Por meio da utilização de PCR em tempo real, western blot e imuno-histoquímica, observou-se uma maior expressão de ISG15 em células luteais grandes no dia 15 da gestação, quando comparada com a expressão em células luteais grandes de ovelhas não prenhes (OLIVEIRA et al., 2008). Adicionalmente, por meio de um ensaio antiviral, foram observadas no dia 15 da gestação bioatividades significativamente maiores de interferons tipo I no sangue da veia uterina, quando comparadas as atividades no sangue da artéria uterina e veia jugular (OLIVEIRA et al., 2008). Assim, foi realizado um outro ensaio antiviral, utilizando soro da veia uterina de animais prenhes no dia 15 da gestação, comparando-o com animais no dia 15 do ciclo estral. Neste ensaio, as amostras dos animais no dia 15 do ciclo estral foram avaliadas sem tratamento e com adição de roIFNT. De modo análogo, as amostras dos animais prenhes no dia 15 da gestação também foram avaliadas sem tratamento e com adição de anticorpo anti-IFNT. Os resultados demonstram baixa atividade antiviral no soro não tratado de animais não prenhes e alta atividade quando foi adicionado roIFNT. Já as amostras dos animais prenhes não tratadas apresentaram alta atividade antiviral, a qual desapareceu quando o soro foi tratado com anticorpo anti-IFNT. Conclui-se que o interferon presente no soro da veia uterina de animais prenhes no dia 15 da gestação é o IFNT, uma vez que sua atividade antiviral foi bloqueda com a utilização de anticorpo específico contra IFNT (BOTT et al., 2010).

A partir da comprovação da presença de IFNT na veia uterina, iniciou-se a investigação de sua ação em tecidos extrauterinos que poderiam estar envolvidos com o reconhecimento materno da gestação (Figura 2). Para tal, um novo modelo de estudo da ação endócrina do IFNT foi desenvolvido (BOTT et al., 2010). Inicialmente, dois diferentes métodos foram testados; o primeiro envolveu uma única injeção de roIFNT na artéria ovariana e o segundo a instalação de uma bomba osmótica para infusão contínua de roIFNT na veia uterina. Os dois métodos foram eficazes e induziram a expressão de ISGs no CL (BOTT et al., 2010). No entanto, a infusão contínua de roIFNT na 


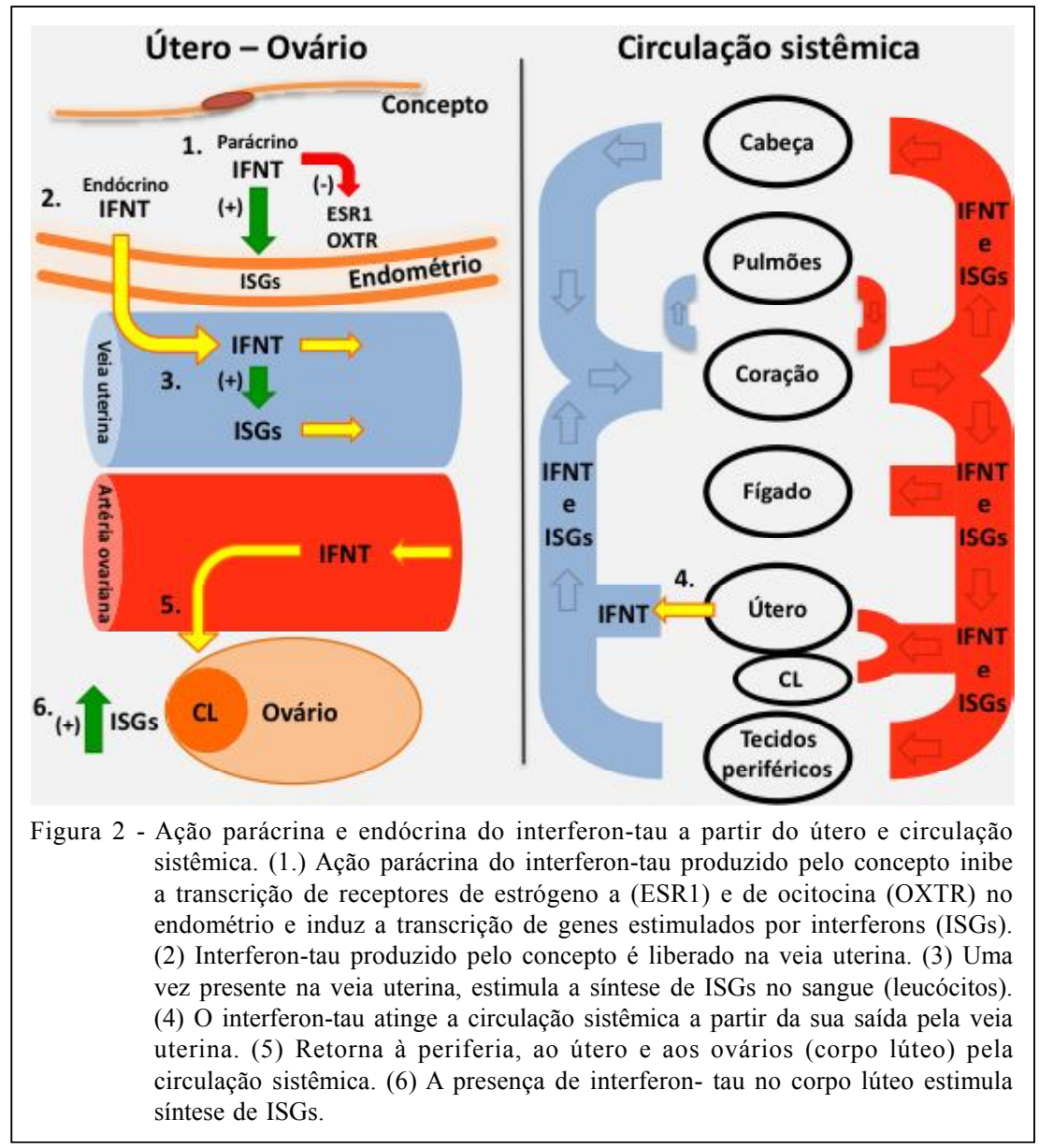

veia uterina resultou em maior expressão de ISG15 luteal quando comparada a injeção única na artéria ovariana. Resultados de um experimento demonstraram que, iniciando dia 10 do ciclo estral, a infusão contínua de roIFNT veia uterina prolongava o intervalo entre estros por mais de 32 dias. As ovelhas tratadas com IFNT, além de não apresentarem cio, foram capazes de manter as concentrações de progesterona sérica elevadas até 32 dias pós-cio (BOTT et al., 2010).

\section{CONCLUSÃO}

No complexo mecanismo de reconhecimento materno da gestação em ruminantes, foi identificado um novo componente: a função endócrina do IFNT. Essa ação do IFNT soma-se a sua conhecida função parácrina, adicionando assim, outra importante variável ao mecanismo. Os dados sugerem que a função endócrina do IFNT pode estar diretamente ligada com a expressão de genes ativados pelo interferon (ISGs). Estes modulam parcial ou totalmente a resistência luteal à ação luteolítica da PGF2 $\alpha$, que por sua vez, e vital no reconhecimento materno da gestação. A ação direta do IFNT em tecidos extrauterinos durante o período de reconhecimento materno da gestação inicia uma nova área para a pesquisa básica. Estudos futuros são necessários para verificar mecanismos de ação do IFNT no CL, bem como em outros tecidos periféricos que possam estar direta ou indiretamente (ação de ISGs) envolvidos com o reconhecimento materno da gestação e/ou resistência luteal à ação da PGF2 $\alpha$ em ruminantes.

\section{REFERÊNCIAS}

AROSH, J.A. et al. Prostaglandin biosynthesis, transport, and signaling in corpus luteum: a basis for autoregulation of luteal function. Endocrinology, v.145, n.5, p.2551-2560, 2004. Disponível em: <http:/ /www.ncbi.nlm.nih.gov/entrez/query.fcgi? cmd=Retrieve\&db=PubMe $\mathrm{d} \&$ dopt=Citation\&list_uids=14736737>. Acesso em: 28 out. 2010. doi: $10.1210 /$ en.2003-1607.

AUSTIN, K.J. et al. Interferon-stimulated gene-15 (Isg15) expression is up-regulated in the mouse uterus in response to the implanting conceptus. Endocrinology, v.144, n.7, p.31073113, 2003. Disponível em: <http://www.ncbi.nlm.nih.gov/ entrez/query.f c gi ? c m d = Retrieve \& d b = P 
$\mathrm{ubMed} \&$ dopt $=$ Citation $\&$ list_uids $=12810567>$. Acesso em: 28 out. 2010. doi: 10.1210/en.2002-0031.

AUSTIN, K.J. et al. Ubiquitin cross-reactive protein is released by the bovine uterus in response to interferon during early pregnancy. Biol Reprod, v.54, n.3, p.600-606, 1996. Disponível em: $<$ http:/ /www.ncbi.nlm.nih.gov/entrez/query.fcgi?cmd=Retrieve \&db=PubMe $\mathrm{d} \& \mathrm{dopt}=$ Citation\&list uids $=8835381>$. Acesso em: 28 out. 2010. doi: $10.1095 /$ ?biolreprod54.3.600

BAZER, F.W. et al. Role of conceptus secretory products in establishment of pregnancy. J Reprod Fertil, v.76, n.2, p.841850, 1986. Disponível em: <http://www.ncbi.nlm.nih.gov/entrez/ q u e r y. f c g i ? c m d $=R$ e $t$ r i e v e \& d b $=$ P u b M ed\&dopt=Citation\&list uids=3517318>. Acesso em: 28 out. 2010.

BEBINGTON, C. et al. Ubiquitin cross-reactive protein gene expression is increased in decidualized endometrial stromal cells at the initiation of pregnancy. Mol Hum Reprod, v.5, n.10, p.966972, 1999. Disponível em: <http://molehr.oxfordjournals.org/ content/5/10/966.long >. Acesso em: 28 out. 2010. doi: 10.1093/ molehr/5.10.966.

BINELLI, M. et al. Bovine interferon-tau stimulates the Janus kinase-signal transducer and activator of transcription pathway in bovine endometrial epithelial cells. Biol Reprod, v.64, n.2, p.654-665, 2001. Disponível em: <http://www.biolreprod.org/ content/64/2/654.long $>$. Acesso em: 28 out. 2010 . doi: 10.1095/?biolreprod64.2.654

BOGAN, R.L.; NISWENDER, G.D. Constitutive steroidogenesis in ovine large luteal cells may be mediated by tonically active protein kinase A. Biol Reprod, v.77, n.2, p.209-216, 2007. Disponível em: $<\mathrm{http} / /$ www.ncbi.nlm.nih.gov/entrez/query.fcgi?cmd=Retrieve \&db=Pub Med\&dopt=Citation\&list_uids=17409373>. Acesso em: 28 out. 2010. doi: 10.1095/biolreprod.106.059618.

BOTT, R.C. et al. Uterine vein infusion of interferon tau (IFNT) extends luteal life span in ewes. Biol Reprod, v.82, n.4, p.725-735, 2010. Disponível em: <http:// www.biolreprod.org/content/82/4/725.full.pdf>. Acesso em: 28 out. 2010. doi: 10.1095/biolreprod.109.079467.

CHEN, Y. et al. Effect of interferon-tau administration on endometrium of nonpregnant ewes: a comparison with pregnant ewes. Endocrinology, v.147, n.5, p.2127-2137, 2006. Disponível em: <http://www.ncbi.nlm.nih.gov/entrez/ que r y. f c g i ? c m d $=$ R e tri e v e $\&$ d b $=$ P u b M e d \& d opt $=$ Citation\&list_uids $=16469802>$. Acesso em: 28 out. 2010. doi: 10.1210 /en.2005-1310.

DAVIS, J.S.; RUEDA, B.R. The corpus luteum: an ovarian structure with maternal instincts and suicidal tendencies. Frontiers in bioscience: a journal and virtual library, v.7, p.1949-1978, 2002. Disponível em: <http://www.rbej.com/ content/pdf/1477-7827-1-94.pdf>. Acesso em: 28 out. 2010. doi: $10.1186 / 1477-7827-1-94$.

DEMMERS, K.J. et al. Trophoblast interferon and pregnancy. Reproduction, v.121, n.1, p.41-49, 2001. Disponível em: $<$ http://www.reproduction-online.org/cgi/reprint/121/1/41>. Acesso em: 28 out. 2010. doi: 10.1530/rep.0.1210041.

EALY, A.D.; YANG, Q.E. Control of interferon-tau expression during early pregnancy in ruminants. Am J Reprod Immunol, v.61, n.2, p.95-106, 2009. Disponível em: <http://
www.ncbi.nlm.nih.gov/entrez/query.fcgi?cmd=Retrieve $\& d b=$ PubMed $\& d o p t=$ Citation\&list_uids=19143673 $>$. Acesso em: 28 out. 2010. doi: 10.1111/j.1600-0897.2008.00673.x.

EZASHI, T. et al. Control of interferon-tau gene expression by Ets-2. Proc Natl Acad Sci U S A, v.95, n.14, p.78827887, 1998. Disponível em: <http://www.pnas.org/content/ 95/14/7882.long $>$. Acesso em: 28 out. 2010.

FARIN, C.E. et al. Expression of trophoblastic interferon genes in sheep and cattle. Biol Reprod, v.43, n.2, p.210-218, 1990. Disponível em: <http://www.biolreprod.org/content/43/ 2/210.long $>$. Acesso em: 28 out. 2010. doi: 10.1095/ ?biolreprod43.2.210.

FARIN, C.E. et al. In situ localization of mRNA for the interferon, ovine trophoblast protein-1, during early embryonic development of the sheep. Mol Endocrinol, v.3, n.7, p.10991107, 1989. Disponível em: <http://mend.endojournals.org/ cgi/reprint/3/7/1099>. Acesso em: 28 out. 2010. doi: 10.1210/ mend-3-7-1099.

FITZ, T.A. et al. Characterization of two steroidogenic cell types in the ovine corpus luteum. Biol Reprod, v.27, n.3, p.703-711, 1982. Disponível em: <http://www.biolreprod.org/ content/27/3/703.long $>$. Acesso em: 28 out. 2010. doi: 10.1095/?biolreprod27.3.703.

FLINT, A.P.F.; SHELDRICK, E.L. Ovarian secretion of oxytocin is stimulated by prostaglandin. Nature, v.297, n.5867, p.587-588, 1982. Disponível em: <http://www.nature.com/ nature/journal/v297/n5867/abs/297587a0.html>. Acesso em: 28 out. 2010 . doi: $10.1038 / 297587 \mathrm{a} 0$.

GIFFORD, C.A. et al. Regulation of interferon-stimulated genes in peripheral blood leukocytes in pregnant and bred, nonpregnant dairy cows. J Dairy Sci, v.90, n.1, p.274-280, 2007. Disponível em: <http://www.journalofdairyscience.org/article/ PIIS0022030207726280/fulltext>. Acesso em: 28 out. 2010. doi: $10.3168 /$ jds.S0022-0302(07)72628-0.

GINTHER, O.J. Internal regulation of physiological processes through local venoarterial pathways: a review. J Anim Sci, v.39, n.3, p.550-564, 1974. Disponível em: <http://jas.fass.org/ cgi/reprint/39/3/550>. Acesso em: 28 out. 2010 .

GODKIN, J.D. et al. Purification and properties of a major, low molecular weight protein released by the trophoblast of sheep blastocysts at day 13-21. J Reprod Fertil, v.65, n.1, p.141-150, 1982. Disponível em: <http://www.reproductiononline.org/cgi/reprint/65/1/141>. Acesso em: 28 out. 2010.

GODKIN, J.D. et al. Ovine trophoblast protein 1, an early secreted blastocyst protein, binds specifically to uterine endometrium and affects protein synthesis. Endocrinology, v.114, n.1, p.120-130, 1984. Disponível em: <http:// endo.endojournals.org/cgi/reprint/114/1/120>. Acesso em: 28 out. 2010. doi: 10.1210/endo-114-1-120.

GRAVES, P.E. et al. Cloning of a receptor for prostaglandin F2 alpha from the ovine corpus luteum. Endocrinology, v.136, n.8, p.3430-3436, 1995. Disponível em: <http:// endo.endojournals.org/cgi/reprint/136/8/3430>. Acesso em: 28 out. 2010 . 
GRAY, C.A. et al. Evidence that absence of endometrial gland secretions in uterine gland knockout ewes compromises conceptus survival and elongation. Reproduction, v.124, n.2, p.289-300, 2002. Disponível em: $<$ http://www.reproductiononline.org/cgi/reprint/124/2/289>. Acesso em: 28 out. 2010.

GUILLOMOT, M. et al. Cellular localization of an embryonic interferon, ovine trophoblastin and its mRNA in sheep embryos during early pregnancy. Biol Cell, v.68, n.3, p.205-211, 1990. Disponível em: < http://www.ncbi.nlm.nih.gov/entrez/ q u e r y. f c g i ? c m d $=\mathrm{R}$ e t r i e v e $\&$ d b $=$ P u b M ed\&dopt $=$ Citation\&list uids $=1695857>$. Acesso em: 28 out. 2010. doi: doi:10.1016/0248-4900(90)90309-Q.

HAN, H. et al. Low blood ISG15 mRNA and progesterone levels are predictive of non-pregnant dairy cows. J Endocrinol, v.191, n.2, p.505-512, 2006. cDisponível em: <http:// joe.endocrinology-journals.org/cgi/reprint/191/2/505>. Acesso em: 28 out. 2010 . doi: 10.1677/joe.1.07015.

HANSEN, T.R. et al. Transient ubiquitin cross-reactive protein gene expression in the bovine endometrium. Endocrinology, v.138, n.11, p.5079-5082, 1997. Disponível em: <http:// endo.endojournals.org/cgi/reprint/138/11/5079>. Acesso em: 28 out. 2010.

HANSEN, T.R. et al. Mechanism of action of interferon-tau in the uterus during early pregnancy. J Reprod Fertil Suppl, v.54, p.329-339, 1999. Disponível em: <http://www.ncbi.nlm.nih.gov/ entrez/query.fcgi ? cmd $=$ Retrieve $\&$ d b $=$ Pub Med $\&$ dopt $=$ Citation\&list_uids $=10692865>$. Acesso em: 28 out. 2010.

HAYASHI, K. et al. Changes in prostaglandin secretion by the regressing bovine corpus luteum. Prostaglandins Other Lipid Mediat, v.70, n.3-4, p.339-349, 2003. Disponível em: <http:// www.ncbi.nlm.nih.gov/entrez/query.fcgi? $\mathrm{cmd}=$ Retrieve $\& \mathrm{db}=\mathrm{PubMe}$ $\mathrm{d} \&$ dopt=Citation\&list_uids=12611498>. Acesso em: 28 out. 2010. doi:10.1016/S0090-6980(02)00148-X.

IMAKAWA, K. et al. Interferon-like sequence of ovine trophoblast protein secreted by embryonic trophectoderm. Nature, v.330, n.6146, p.377-379, 1987. Disponível em: <http:/ /www.ncbi.nlm.nih.gov/entrez/query.fcgi?cmd=Retrieve $\& \mathrm{db}=\mathrm{Pu}$ bMed\&dopt $=$ Citation\&list_uids $=2446135>$. Acesso em: 28 out. 2010. doi: $10.1038 / 330377 \mathrm{a} 0$.

JOHNSON, G.A. et al. Expression of the interferon tau inducible ubiquitin cross-reactive protein in the ovine uterus. Biol Reprod, v.61, n.1, p.312-318, 1999.c Disponível em: <http:/ /www.biolreprod.org/content/61/1/312.long>. Acesso em: 28 out. 2010. doi: 10.1095/?biolreprod61.1.312.

JOHNSON, G.A. et al. Effects of the estrous cycle, pregnancy, and interferon tau on 2',5'-oligoadenylate synthetase expression in the ovine uterus. Biol Reprod, v.64, n.5, p.1392-1399, 2001. Disponível em: <http://www.biolreprod.org/content/64/ 5/1392.full>. Acesso em: 28 out. 2010. doi: 10.1095/ ?biolreprod64.5.1392.

KENNY, N. et al. Morphometric quantification of mitochondria in the two steroidogenic ovine luteal cell types. Biol Reprod, v.40, n.1, p.191-196, 1989. Disponível em: <http:// www.biolreprod.org/content/40/1/191.long>. Acesso em: 28 out. 2010. doi: 10.1095/?biolreprod40.1.191.
KERBLER, T.L. et al. Relationship between maternal plasma progesterone concentration and interferon-tau synthesis by the conceptus in cattle. Theriogenology, v.47, n.3, p.703714, 1997. Disponível em: <http://www.theriojournal.com/ article/S0093-691X\%2897\%2900028-9/pdf>. Acesso em: 28 out. 2010. doi: S0093-691X(97)00028-9 [pii].

LOEB, K.R.; A. L. HAAS. The interferon-inducible 15-kDa ubiquitin homolog conjugates to intracellular proteins. J Biol Chem, v.267, n.11, p.7806-7813, 1992. Disponível em: $<$ http://www.jbc.org/content/267/11/7806.long >. Acesso em: 28 out. 2010 .

MARTAL, J. et al. Trophoblastin, an antiluteolytic protein present in early pregnancy in sheep. J Reprod Fertil, v.56, n.1, p.63-73, 1979. Disponível em: <http://www.reproductiononline.org/cgi/reprint/56/1/63>. Acesso em: 28 out. 2010. doi: $10.1530 /$ jrf.0.0560063.

MCCRACKEN, J.A. et al. The role of prostaglandins in luteal regression. J Reprod Fertil Suppl, v.18, p.133-42. 1973. Disponível em: <http://www.ncbi.nlm.nih.gov/entrez/ qu e r y. f c g i ? c m d $=$ R e t r i e v e \& d b $=$ P u b M ed\&dopt $=$ Citation\&list_uids $=4580250>$. Acesso em: 28 out. 2010 .

MCCRACKEN, J.A. et al. Luteolysis: a neuroendocrine-mediated event. Physiol Rev, v.79, n.2, p.263-323, 1999. Disponível em: $<\mathrm{ht} \mathrm{tp://www.ncbi.n} 1 \mathrm{~m}$. nih.gov/entrez/ que ry.f c g i ? c m d $=\mathrm{R}$ e trie ve $\& d b=P$ u b M e d\&dopt=Citation\&list_uids=10221982>. Acesso em: 28 out. 2010.

MCCRACKEN, J.A. et al. Corpus luteum regression induced by prostagland in F2-alpha. J Clin Endocrinol Metab, v.30, n.4, p.544-546, 1970 .

MIRANDO, M.A. et al. Stimulation of 2',5'-oligoadenylate synthetase activity in sheep endometrium during pregnancy, by intrauterine infusion of ovine trophoblast protein-1, and by intramuscular administration of recombinant bovine interferon-alpha I1. J Reprod Fertil, v.93, n.2, p.599-607, 1991. Disponível em: <http:// www.ncbi.nlm.nih.gov/entrez/query.fcgi? $\mathrm{cmd}=$ Retrieve $\& \mathrm{db}=\mathrm{Pu}$ bMed\&dopt=Citation\&list_uids $=1787480>$. Acesso em: 28 out. 2010.

MOOR, R.M.; ROWSON, L.E. Local uterine mechanisms affecting luteal function in the sheep. J Reprod Fertil, v.11, n.2, p.307310, 1966. Disponível em: <http://www.ncbi.nlm.nih.gov/entrez/ que r y.f c g i ? c m d $=\mathrm{R}$ e t r i e v e $\& \mathrm{~d} b=\mathrm{P} \mathrm{u} \mathrm{b} \mathrm{M}$ ed\&dopt $=$ Citation\&list_uids=5949293>. Acesso em: 28 out. 2010.

NAIVAR, K.A. et al. Secretion of bovine uterine proteins in response to type I interferons. Biol Reprod, v.52, n.4, p.848854, 1995. Disponível em: <http://www.biolreprod.org/content/ 52/4/848.full.pdf + html $>$. Acesso em: 28 out. 2010. doi: 10.1095/?biolreprod52.4.848.

NARUMIYA, S. et al. Prostanoid receptors: structures, properties, and functions. Physiol Rev, v.79, n.4, p.1193226, 1999. Disponível em: <http://physrev.physiology.org/ cgi/reprint/79/4/1193>. Acesso em: 28 out. 2010.

NISWENDER, G. D. Molecular control of luteal secretion of progesterone. Reproduction, v.123, n.3, p.333-339. 2002. Disponível em: <http://www.reproduction-online.org/cgi/reprint/ 123/3/333>. Acesso em: 28 out. 2010. doi: 10.1530/ rep. 0.1230333 . 
NISWENDER, G.D. et al. Mechanisms controlling the function and life span of the corpus luteum. Physiol Rev, v.80, n.1, p.1-29, 2000. Disponível em: <http://www.ncbi.nlm.nih.gov/ e n t r e z / q u e r y. f c g i ? c m d = R e t r i e v e \& d b $=$ P $\mathrm{ubMed} \& d o p t=$ Citation\&list_uids $=10617764>$. Acesso em: 28 out. 2010

NISWENDER, G.D. et al. Regulation of luteal function in domestic ruminants: new concepts. Recent Prog Horm Res, v.41, p.101-51. 1985. Disponível em: <http:// www.ncbi.nlm.nih.gov/entrez/query.fcgi? $\mathrm{cmd}=$ Retrieve $\& \mathrm{db}=\mathrm{Pub}$ Med\&dopt $=$ Citation\&list_uids $=2996087>$. Acesso em: 28 out. 2010 .

OLIVEIRA, J.F. et al. Expression of interferon (IFN)-stimulated genes in extrauterine tissues during early pregnancy in sheep is the consequence of endocrine IFN-tau release from the uterine vein. Endocrinology, v.149, n.3, p.1252-1259, 2008. Disponível em: <http:// www.ncbi.nlm.nih.gov/entrez/query.fcgi? $\mathrm{cmd}=$ Retrieve $\& \mathrm{db}=\mathrm{PubM}$ ed\&dopt=Citation\&list_uids=18063687>. Acesso em: 28 out. 2010. doi: 10.1210/en.2007-0863.

OTT, T.L. et al. Effects of the estrous cycle and early pregnancy on uterine expression of $\mathrm{mx}$ protein in sheep (Ovis aries). Biol Reprod, v.59, n.4, p.784-794, 1998. Disponível em: $<$ http://www.biolreprod.org/cgi/content/abstract/59/4/784 >. Acesso em: 28 out. 2010.

PERRY, D.J. et al. Cloning of interferon-stimulated gene 17: the promoter and nuclear proteins that regulate transcription. Mol Endocrinol, v.13, n.7, p.1197-1206, 1999. Disponível em: <http:/ /www.ncbi.nlm.nih.gov/entrez/query.fcgi?cmd=Retrieve \&db=PubM ed\&dopt $=$ Citation\&list_uids $=10406469>$. Acesso em: 28 out. 2010.

PIERCE, K. L. et al. Cloning of a carboxyl-terminal isoform of the prostanoid FP receptor. J Biol Chem, v.272, n.2, p.8838877, 1997. Disponível em: <http://www.ncbi.nlm.nih.gov/ en trez/query.f c gi ? c m d = Retrie ve \& d b $=$ P u b M ed\&dopt $=$ Citation\&list_uids $=8995377>$. Acesso em: 28 out. 2010.

ROBERTS, R.M. A role for interferons in early pregnancy. Bioessays, v.13, n.3, p.121-126, 1991. Disponível em: <http:// www.ncbi.nlm.nih.gov/entrez/query.fcgi? $\mathrm{cmd}=$ Retrieve $\& \mathrm{db}=\mathrm{PubMe}$ $\mathrm{d} \&$ dopt=Citation\&list_uids=1872822>. Acesso em: 28 out. 2010. doi: $10.1002 /$ bies. 950130305 .

ROBERTS, R.M. et al. Interferons and the maternal-conceptus dialog in mammals. Semin Cell Dev Biol, v.19, n.2, p.170177, 2008. Disponível em: <http://www.ncbi.nlm.nih.gov/ entrez/query.fcgi ? cmd $=$ Retrieve $\&$ db $=$ PubMed \& dopt=Citation\&list_uids=18032074>. Acesso em: 28 out. 2010. doi: $10.1016 /$ j.semcdb.2007.10.007.

ROBERTS, R.M. et al. Unique features of the trophoblast interferons. Pharmacol Ther, v.51, n.3, p.329-345 1991. Disponível em: <http:/ /www.ncbi.nlm.nih.gov/entrez/query.fcgi? cmd=Retrieve $\& \mathrm{db}=\mathrm{PubMe}$ $\mathrm{d} \& \mathrm{dopt}=$ Citation\&list_uids $=1724322>$. Acesso em: 28 out. 2010. doi: 0163-7258(91)90064-S [pii].

ROBERTS, R.M. et al. Interferons as hormones of pregnancy. Endocrine Reviews, v.13, n.3, p.432-452, 1992. Disponível em: <http://edrv.endojournals.org/cgi/content/abstract/13/3/ 432http://edrv.endojournals.org>. Acesso em: 28 out. 2010.
ROBERTS, R.M. et al. Evolution of the interferon tau genes and their promoters, and maternal-trophoblast interactions in control of their expression. Reprod Suppl, v.61, p.239-351, 2003. Disponível em: <http://www.ncbi.nlm.nih.gov/entrez/ qu e r y. f c g i ? c m d $=\mathrm{R}$ e trie v e \& d b $=\mathrm{P} \mathrm{u} \mathrm{b} \mathrm{M} \mathrm{e}$ $\mathrm{d} \&$ dopt $=$ Citation\&list_uids $=14635939>$. Acesso em: 28 out. 2010 .

ROBERTS, R.M. et al. Interferon production by the preimplantation sheep embryo. J Interferon Res, v.9, n.2, p.175-187, 1989. Disponível em: <http://www.ncbi.nlm.nih.gov/ pubmed/2469745>. Acesso em: 28 out. 2010.

ROBERTS, R.M. et al. Maternal recognition of pregnancy. Biol Reprod, v.54, n.2, p.294-302, 1996. Disponível em: < h t t p :// w w w. n c bi.n 1 m.ni h. gov/ent rez/ query.fcgi? $\mathrm{cmd}=$ Retrieve $\& \mathrm{db}=\mathrm{PubMed} \& \mathrm{dopt}=$ Citation\&list_uids $=8788179$ >. Acesso em: 28 out. 2010 .

ROSENFELD, C.S. et al. Expression of interferon receptor subunits, IFNAR1 and IFNAR2, in the ovine uterus. Biol Reprod, v.67, n.3, p.847-853, 2002. Disponível em: <http:// www.biolreprod.org/content/67/3/847.full.pdf + html $>$. Acesso em: 28 out. 2010 . doi: 10.1095/?biolreprod.102.004267.

SAKAMOTO, K. et al. Molecular cloning and expression of a cDNA of the bovine prostaglandin F2 alpha receptor. J Biol Chem, v.269, n.5, p.3881-3886, 1994. Disponível em: <http:// www.ncbi.nlm.nih.gov/entrez/query.fcgi? cmd=Retrieve $\& \mathrm{db}=$ PubMed $\&$ dopt $=$ Citation\&list_uids $=7508922>$. Acesso em: 28 out. 2010.

SCHMITT, R.A. et al. Uterine cellular changes in 2',5'-oligoadenylate synthetase during the bovine estrous cycle and early pregnancy. Biol Reprod, v.48, n.3, p.460-466, 1993. Disponível em: <http:/ /www.ncbi.nlm.nih.gov/entrez/query.fcgi?cmd=Retrieve \&db=PubM ed\&dopt $=$ Citation\&list_uids $=8452923>$. Acesso em: 28 out. 2010.

SCHUSTER, V.L. Molecular mechanisms of prostaglandin transport. Annu Rev Physiol, v.60, p.221-242, 1998. Disponível em: <http://www.ncbi.nlm.nih.gov/entrez/ que r y. f c g i ? c m d $=$ R e t r i e v e $\&$ d b $=$ P u b M e $\mathrm{d} \& \mathrm{dopt}=$ Citation\&list_uids $=9558462>$. Acesso em: 28 out. 2010. doi: 10.1146/annurev.physiol.60.1.221.

SHIRASUNA, K. et al. Positive association, in local release, of luteal oxytocin with endothelin 1 and prostaglandin F2alpha during spontaneous luteolysis in the cow: a possible intermediatory role for luteolytic cascade within the corpus luteum. Biol Reprod, v.76, n.6, p.965-970, 2007. Disponível em: <http:/www.biolreprod.org/content/76/6/965.full>. Acesso em: 28 out. 2010 . doi: 10.1095/?biolreprod.106.057554.

SPENCER, T.E.; BAZER, F.W. Ovine interferon tau suppresses transcription of the estrogen receptor and oxytocin receptor genes in the ovine endometrium. Endocrinology, v.137, n.3, p.11441147, 1996. Disponível em: <http://www.ncbi.nlm.nih.gov/entrez/ que r y. f c g i ? c m d $=\mathrm{R}$ e tri e v e $\&$ d b $=\mathrm{P} \mathrm{u} \mathrm{b} \mathrm{M} \mathrm{e}$ $\mathrm{d} \& \mathrm{dopt}=$ Citation\&list_uids $=8603586>$. Acesso em: 28 out. 2010.

SPENCER, T.E. et al. Implantation mechanisms: insights from the sheep. Reproduction, v.128, n.6, p.657-668, 2004. Disponível em: <http:/www.reproduction-online.org/cgi/reprint/ 128/6/657>. Acesso em: 28 out. 2010 . doi: 10.1530/ rep. 1.00398 . 
SPENCER, T.E. et al. Differential effects of intrauterine and subcutaneous administration of recombinant ovine interferon tau on the endometrium of cyclic ewes. Biol Reprod, v.61, n.2, p.464-470, 1999. Disponível em: <http:// www.biolreprod.org/content/61/2/464.long $>$. Acesso em: 28 out. 2010. doi: 10.1095/?biolreprod61.2.464.

THATCHER, W.W. et al. Uterine-conceptus interactions and reproductive failure in cattle. Theriogenology, v.56, n.9, p.1435-1450, 2001. Disponível em: <http:// www.theriojournal.com/article/S0093-691X\%2801\%29006458/pdf>. Acesso em: 28 out. 2010.

WATHES, D.C.; LAMMING, G.E. The oxytocin receptor, luteolysis and the maintenance of pregnancy. J Reprod Fertil Suppl, v.49, p.53-67, 1995. Disponível em: <http:// www.ncbi.nlm.nih.gov/entrez/query.fcgi? $\mathrm{cmd}=$ Retrieve $\& \mathrm{db}=\mathrm{Pub}$ Med\&dopt=Citation\&list_uids=7623343>. Acesso em: 28 out. 2010 .

WILTBANK, M.C. et al. Prostaglandin F2 alpha receptors in the early bovine corpus luteum. Biol Reprod, v.52, n.1, p.7478, 1995. Disponível em: <http://www.ncbi.nlm.nih.gov/entrez/ qu e r y. f c g i ? c m d $=$ R e trie v e $\& d b=P$ u b M ed\&dopt $=$ Citation\&list_uids $=7711186>$. Acesso em: 28 out. 2010 .

YANKEY, S.J. et al. Expression of the antiviral protein $\mathrm{Mx}$ in peripheral blood mononuclear cells of pregnant and bred, nonpregnant ewes. J Endocrinol, v.170, n.2, p.R7-R11, 2001. Disponível em: $<$ http://joe.endocrinology-journals.org/cgi/ reprint/170/2/R7>. Acesso em: 28 out. 2010. doi: 10.1677/ joe.0.170R007.

ZARCO, L. et al. Modification of prostaglandin F-2 alpha synthesis and release in the ewe during the initial establishment of pregnancy. J Reprod Fertil, v.83, n.2, p.527-536, 1988a. Disponível em: <http://www.ncbi.nlm.nih.gov/entrez/ que ry.f c g i ? c m d $=$ R e trie ve $\&$ d b $=$ P u b M e d \& dopt $=$ Citation\&list_uids $=3166070>$. Acesso em: 28 out. 2010.

ZARCO, L. et al. Release of prostaglandin F-2 alpha and the timing of events associated with luteolysis in ewes with oestrous cycles of different lengths. J Reprod Fertil, v.83, n.2, p.51726. 1988b. Disponível em: <http://www.ncbi.nlm.nih.gov/ entrez/query.fcgi ? cmd =Retrieve $\& d b=P$ ubMed $\&$ dopt $=$ Citation\&list_uids $=3166069>$. Acesso em: 28 out. 2010 . 